\title{
Cultivando proliferações indomáveis: considerações antropológicas sobre as políticas de proteção à infância
}

\section{Cultivating feral proliferations: anthropological considerations on child protection policies}

\author{
Claudia Fonseca' \\ https://orcid.org/0000-0002-7761-6095 \\ claudialwfonseca@gmail.com \\ ' Universidade Federal do Rio Grande do Sul - Porto Alegre, RS, Brasil
}




\title{
Resumo
}

Por uma reflexão voltada para políticas de adoção infantil, procuro estabelecer uma ponte entre, por um lado, episódios etnográficos - densos e contextualmente situados - e, por outro, sistemas abrangentes com consequências em larga escala e de longo alcance. Operacionalizo essa proposta pela análise das infraestruturas administrativa, estatística e burocrática que conectam as filosofias políticas do momento às atitudes e ações dos variados atores (profissionais, servidores e usuários) sob observação. Essa abordagem permite rastrear através das últimas décadas os instrumentos tecnológicos - em particular, estatísticas, cadastros e formulários - cunhados para estabilizar determinadas políticas de adoção. Ao mesmo tempo, atento às "proliferações" (Tsing; Mathews; Bubandt, 2019) - produto e produtor de tensões do próprio sistema - que levam acontecimentos em direções inesperadas. Ao apreciar esses eventos que iniciam quase sempre em escala limitada e com consequências incertas, minha intenção é restituir o poder desses exemplos a alimentar certa esperança - profundamente pragmática, epistemologicamente ambivalente e subarticulada - em possibilidades futuras ainda sequer imaginadas.

Palavras-chave: antropologia de infraestrutura; tecnologias de governo; políticas públicas; adoção infantil.

\begin{abstract}
In the following reflection on child adoption policies, we seek to establish a bridge between, on the one hand, ethnographic episodes - dense and contextually situated and, on the other hand, comprehensive systems with large-scale and far-reaching consequences. To carry out this endeavour we analyze the administrative, statistical and bureaucratic infrastructures connecting political philosophies of the moment to the attitudes and actions of the various actors (professionals, servants and users) under observation. This approach allows us to trace throughout the past few decades of technological instruments - in particular, statistics, registries and forms -, designed to stabilize certain adoption policies. At the same time, we pay close attention to "proliferations" (Tsing; Mathews; Bubandt, 2019) - product and producer of tensions in the system itself - that conduct matters in unexpected directions. In appreciating these events that almost always start on a limited scale and with uncertain consequences, our intention is to enhance the power of these examples to nurture a certain hope - deeply pragmatic, epistemologically ambivalent and subarticulated - in yet unfathomed possibilities.
\end{abstract}

Keywords: anthropology of infrastructure; technologies of government; public policies; child adoption. 
Ao examinar paisagens de governo neoliberal, procuro neste artigo identificar regiões "remendadas" para explorar meu objetivo um tanto paradoxal: o de cultivar o indomável, isto é, de dar visibilidade à produtividade dos muitos elementos que fogem dos esquemas simplificados dos projetos de intervenção social. Transpondo a proposta analítica de Tsing, Mathews e Bubandt (2019) originalmente formulada para o debate sobre a antropocena para outra arena - a da proteção à infância e, em particular, a adoção de crianças -, meu intuito é enfrentar questões que se apresentam com cada vez mais urgência: como elaborar pesquisas e formular conclusões de modo a promover sua relevância diante de cenários problemáticos da atualidade? Como pôr nossas descrições de circunstâncias específicas e vidas palpáveis a serviço de conceitos que abrem brechas em cenários assombrados pelo fantasma de forças inexoráveis?

Antropólogos, há tempo, vêm se inquietando com a lógica simplificada que permeia as políticas públicas. O planejamento em grande escala tende quase inevitavelmente a ser esquemático, apoiando-se em métodos quantitativos que constroem a realidade através de uma "avalanche de números" (Desrosières, 1993; Hacking, 1990; Scott, 1998; Shore; Wright, 1997). Porém, como alertam Tsing, Mathews e Bubandt (2019), essas simplificações modulares - "entidades provisoriamente congeladas" construídas em geral a partir de dados agregados - falam mais de futuros imaginados do que de experiências vividas, relegando a complexidade do mundo a um segundo plano. Nos modelos abstratos das políticas públicas, as formas de vida não previstas no plano original são facilmente reduzidas a meras "exceções à regra", se não completamente ignoradas:

As rotinas da coleta de dados e da construção de modelos minam a capacidade de planejadores de notar mudança, transformação e especificidade histórica no mundo. Os modelos se afirmam como infraestruturas informacionais que ao mesmo tempo facilitam e embrutecem a observação. (Tsing; Mathews; Bubandt, 2019, p. 191, tradução minha).

Além de render a heterogeneidade invisível, a lógica modular torna o heterodoxo impensável. Em outras palavras, não só produz políticas em descompasso com a realidade, também censura a imaginação, privando de palavras maneiras diversas de ser e estar no mundo. 
A antropologia, sabemos bem, se destaca em revelar a heterogeneidade do mundo. Porém, sem formular suas observações num estilo inteligível aos planejadores, sem se engatar em conversas transdisciplinares sobre estruturas globalmente consequentes, suas contribuições arriscam cair em ouvidos moucos. Por isso, Tsing, Mathews e Bubandt (2019) exortam seus colegas a ousar fazer mais do que restituir a voz "de alteridades paroquiais". Recomendam, em vez disso, uma abordagem interescalar que explora a possibilidade de rasgas e "remendos" nas paisagens empíricas produzidas pelas políticas de grande alcance. Isto é, através de etnografias em circunstâncias bem situadas, procuram restituir histórias contingentes que mostram tanto as fissuras como as reconfigurações de contextos que, à primeira vista, pareciam pacificamente domadas pela intervenção planejada.

Central à proposta de Tsing e seus coautores é a ideia de "proliferações selvagens" (feral proliferations) - cunhada para designar os inevitáveis eventos imprevistos que surgem nas topografias irregulares do mundo real. Tal como a uso neste artigo, a noção evoca as constantes costuras exigidas no andamento prático de qualquer sistema, por ideal que este seja no plano abstrato. Criando-se nas lacunas da lógica modular, as proliferações (de ordem híbrida, incluindo atores orgânicos e inorgânicos, materiais e etéreos, burocráticos e tecnológicos) fogem do controle disciplinar. Sem nenhuma função predeterminada em relação ao todo, podem ser lidas ora como enjambrações que permitem o sistema se perpetuar, ora como rebeldes com capacidade de escangalhar as engrenagens, ora como fonte de esperança, capaz de provocar mudanças surpreendentes.

Na presente reflexão voltada para políticas de proteção à infância, inspiro-me nas orientações de Tsing, Mathews e Bubandt (2019) para procurar uma ponte entre, por um lado, episódios etnográficos - densos e contextualmente situados - e, por outro, sistemas abrangentes com consequências em larga escala e de longo alcance. Operacionalizo essa proposta pela análise das infraestruturas administrativa, estatística e burocrática que conectam as filosofias políticas do momento às atitudes e ações dos variados atores (profissionais, servidores e usuários) sob observação. ${ }^{1}$ Essa abordagem permite

1 Parafraseando Larkin (2013, p. 328), concebo infraestruturas como redes construídas para facilitar o fluxo de bens, pessoas ou ideias, permitindo seu intercâmbio através do tempo e do espaço. São compostas de formas materiais e relações, funcionando como veículos semióticos e estéticos, que condicionam a natureza dos fluxos, suas temporalidades e sua vulnerabilidade ao colapso. 
escrutinar os instrumentos tecnológicos - estatísticas, cadastros e formulários - que servem para implantar determinadas políticas de proteção e, ao mesmo tempo, revelam as "proliferações" que abrem brechas e provocam guinadas não programadas.

Aproveitando as lições fornecidas por outros estudos antropológicos de infraestrutura (Bowker; Star, 1999; Gupta, 2012; Hirata et al., 2019; Larkin, 2013; Schuch, 2018), parto da hipótese de que, não obstante a aparência de uma racionalidade exemplar, a abundância de números, gráficos e tabelas que subjaz à legibilidade do Estado não significa necessariamente um conhecimento abrangente da realidade, nem a possibilidade de diagnosticar problemas ou atribuir responsabilidades na execução de políticas sociais consequentes. Minha análise se calca na premissa de que, para alcançar tais objetivos, é preciso ir além da racionalidade abstrata e chegar nas moralidades burocráticas, valores do senso comum, e emoções individuais que se mesclam inevitavelmente não só nos interstícios, mas nas próprias engrenagens do sistema administrativo de governo.

O tema da adoção infantil oferece um exemplo por excelência dessa mescla entre valor, burocracia e emoção. Tratando de uma figura já moralmente carregada ("a criança"), provoca disputas políticas acirradas quanto aos direitos e deveres das diferentes categorias envolvidas. Em particular, no bojo das recentes políticas neoliberais de austeridade, despontam questões sobre a distribuição de responsabilidade pelo problema de crianças em situação de grande vulnerabilidade. Uma consideração superficial das leis e políticas escoradas na chamada transparência da boa governança (Ballestero, 2012) dá a impressão de que houve uma resposta coerente e eficaz a muitas dessas questões. Contudo, se olhamos de mais perto, atentando para as heterogêneas mediações que operacionalizam o sistema, emerge um quadro bem mais complexo.

Assim, nos parágrafos a seguir, rastreio ao longo dos últimos 30 anos as infraestruturas que conectam as esferas local e global, disseminando ideias e padronizando comportamentos no campo da proteção à infância. Ao mesmo tempo, atento para as múltiplas proliferações, manifestas em forma ora de movimentos de protesto, ora de fissuras nas mediações burocráticas, ora de novos atores que, embora engendrados pelo sistema, desviam radicalmente do desenho previsto. Ao apreciar esses acontecimentos que iniciam quase sempre em escala limitada e com consequências incertas, minha intenção é restituir o poder dos 
exemplos empíricos a alimentar certa esperança - profundamente pragmática, epistemologicamente ambivalente e subarticulada (Tsing; Mathews; Bubandt, 2019, p. 193) - em possibilidades futuras ainda sequer imaginadas.

\section{Metas e escalas nos registros oficiais}

Em fevereiro de 2021, saiu nos jornais brasileiros um artigo sobre a adoção irregular de um menino no início dos anos 1980 por pais holandeses (Pinto, 2021). A obstinação deste adotado, já com 40 anos, em seguir a pista de suas origens não só comoveu a opinião pública no Brasil. Motivou o governo holandês a rever sua tolerância, velha de diversas décadas, a adoções internacionais embasadas em documentação duvidosa. Esse incidente introduz um elemento de suma relevância para nossa discussão. As conexões globais de qualquer sistema de proteção à infância fazem com que seja quase impossível realizar uma análise de políticas de adoção como se tratasse de um fenômeno de escala estritamente nacional.

Existe, entre acadêmicos e profissionais da área, uma narrativa bastante consensual sobre a história recente da adoção - pelo menos no Ocidente (Ballard et al., 2015). Logo depois da Segunda Guerra Mundial, surgindo primeiro no mundo anglo-saxão antes de se espalhar para os demais países, a adoção plena se apresentava como um avanço moral quase indiscutível - um gesto humanitário que beneficiava todos. Não só dotava crianças necessitadas de um lar, também aliviava a mãe solteira da vergonha de ter um filho bastardo e permitia a pessoas inférteis realizarem seu sonho de família. Foi apenas com os movimentos de direitos civis e descolonização dos anos 1970 que surgiram dúvidas sobre um possível lado obscuro do processo.

Os povos indígenas no hemisfério norte passaram a denunciar o que consideravam o "roubo" sistemático de seus filhos - sequestrados em internatos longe de suas famílias ou mesmo adotados por casais brancos. Nos Estados Unidos, os afro-americanos se revoltaram contra a multiplicação de adoções transraciais, tal como pouco tempo depois, governos do hemisfério sul (Brasil, Índia, Guatemala, etc.) reagiriam contra a sangria de crianças saindo em adoção transnacional para pais adotivos no Norte global. Mas quem mais contribuiu para denunciar a extrema desigualdade política e econômica que permeava a grande 
maioria de processos de adoção foram as Abuelas de la Plaza de Mayo. A trágica experiência da ditadura argentina, com o sequestro sistemático de filhos de perseguidos políticos, deu origem a diversas cláusulas da Convenção dos Direitos da Criança em 1989 (Villalta; Gesteira, 2019). Nesses diversos momentos de protesto, encontramos um primeiro exemplo das proliferações imprevistas, surgidas em situações locais específicas, no bojo do processo global de adoção infantil. Esses vários eventos provocaram uma reavaliação crítica da adoção que, pela Convenção de Haia, ${ }^{2}$ assim como vários tratados e leis subsequentes (nacionais como internacionais), viria a redirecionar o sistema. A consciência da vulnerabilidade não só de certas famílias, mas de populações inteiras, exigia medidas vigorosas para prevenir abusos de poder que, até então, sob justificação humanitária, tinham redundado na abdução sumária de crianças.

Cabe notar que esse vaivém de novas atitudes entre as esferas nacional e internacional passa não só por normativas oficiais (ver Ribeiro, 2018), mas também por instrumentos estatísticos. Na área da infância, a adoção internacional foi sem dúvida um dos primeiros palcos onde os números comparando o status dos diferentes países serviram para disseminar certa consciência crítica. Quando alto, esse número ressaltava a vergonha de um país "fornecedor" de crianças; quando baixo, servia para lavar a honra nacional. No Brasil, observamos uma clara conexão entre os escândalos publicados nos jornais ao longo dos anos 1980 e o surgimento de um registro, centralizado pelo Ministério de Justiça, de adoções realizadas por adotantes estrangeiros. Assim, particularmente depois da Convenção de Haia (1993), o governo pôde mostrar a queda dramática de adoções internacionais (de 2000 por ano no fim dos anos 1980 para menos de 400 dez anos depois), assinalando aos cidadãos brasileiros e ao mundo que tinha a situação sob controle.

Com o tempo, virou praxe, da parte de organizações internacionais (da OECD à Unicef e WHO), usar estatísticas comparativas para induzir os diferentes governos nacionais a padronizar suas metas - que digam respeito a taxas de desemprego, doenças infecciosas, educação ou violações de direitos humanos (Merry, 2011). A lógica do benchmarking - isto é, a hierarquização de nações à base de indicadores numéricos -, seria um modo eficaz de disseminar

2 Convenção Relativa à Proteção das Crianças e à Cooperação em Matéria de Adoção Internacional (1993). 
certa agenda de prioridades sem recorrer a sanções coercitivas ou restrições legais (Bruno; Didier, 2013). A quantificação da "performance", tornada pública na forma de ranking, deixaria escancarado o lugar de cada país em relação a outros, incitando os mais "atrasados" a emular os melhor colocados. Dessa maneira, o teor político das metas fica em segundo plano, ofuscado pelo brilho das ferramentas técnicas.

Por louvável que sejam os objetivos, e por palpáveis que sejam os avanços realizados em muitas áreas, é interessante observar como a mediação numérica pode virar um fim em si, induzindo distorções no próprio registro de dados. $\mathrm{Na}$ área da infância, pode-se citar, entre muitos outros exemplos, as campanhas da Unicef que, ao operacionalizar um direito declarado na Convenção dos Direitos da Criança, levaram a partir da virada do milênio a uma campanha vigorosa para o pronto registro em cartório de recém-nascidos (United Nations Children's Fund, 2013). Em 2015, o governo brasileiro - sem dúvida feliz de incluir o país no ranking dos mais "avançados" - anunciou que o sub-registro de nascimentos no Brasil tinha sido praticamente erradicado, caindo de $23 \%$ em 2001 para 1\%. Entretanto, não tardou para uma reavaliação mostrar que o dado real era mais de três vezes maior, retratando uma realidade longe ainda do ideal (Instituto Brasileiro de Geografia e Estatística, 2020). (O fato de que em 2021 o Ministério da Mulher, da Família e dos Direitos Humanos ainda abrigue no seu site a notícia errônea de 2015 é sintomático da admiração acrítica que tal anúncio provoca. $\left.{ }^{3}\right)$

Na confecção de registros numéricos, é possível que existam ainda outras motivações para distorcer ou até mesmo encobrir certas informações. Funcionários procurando agradar seus supervisores e melhorar o ranking do país podem encontrar jeitos para minimizar fatos que destoam das metas internacionais. Seria um caso clássico de "ignorância estratégica", termo cunhado por McGoey (2012) para evocar a maneira com que organizações (públicas e privadas) omitem informações inquietantes a fim de manter o reconhecimento de sua expertise e a confiança no seu controle sobre os acontecimentos. Juntando estratégias conscientes (a reformulação de categorias que realçam êxitos) com táticas informais (funcionários que resistem em documentar seus casos

3 Cf. Brasil... (2015). 
"fracassados"), o esforço institucional opera à base da tolerância tácita de certas omissões. À medida que nos aproximamos dos profissionais mediadores dos sistemas de proteção à infância - os que avaliam comportamentos e classificam situações - podemos considerar em maior detalhe esse jogo de luz e sombra nas informações oficiais.

\section{Adoções nacionais: opacidades, ambiguidades e angústias nas mediações infraestruturais}

Em torno de 2013 estourou na mídia mexicana um escândalo deflagrado pela denúncia de uma mulher indígena alegando que seu filho tinha sido retirado e dado em adoção contra sua vontade. Conforme a antropóloga acompanhando este caso, o setor legal do Departamento de Proteção Integral à Infância foi logo cobrado por superiores querendo uma prestação de contas não só daquela adoção, mas de todas as adoções domésticas realizadas desde o ano 2000. A demanda criou, entre funcionários do serviço, certa confusão, pois não conseguiam produzir os registros exigidos - aparentemente perdidos nos arquivos mortos da administração. Em conversa com o chefe do setor, a antropóloga (já presente no serviço quando o problema estourou) registrou as ambivalências de seu interlocutor sobre essa busca de informações. Os arquivos mortos representavam uma faca de dois gumes. Por um lado, a produção de documentos consistentes poderia aumentar a credibilidade do setor. Por outro lado, os arquivos também poderiam revelar práticas irregulares, colocando a nu o caráter arbitrário de certas decisões (Reyes-Kipp, 2016; ver também Gupta, 2012). Ao avançar na etnografia dos vários procedimentos burocráticos da administração, a analista acaba por demonstrar de forma convincente exatamente quão arbitrários podem ser os trâmites de uma adoção. ${ }^{4}$

Apesar de situada a milhares de quilômetros de distância, a opacidade de informações no serviço mexicano não deixa de lembrar algo do que acontecia até pouco tempo atrás no Brasil. Aqui, enquanto já nos anos 1980 o número de

4 Por exemplo, na sua pressa de classificar uma criança acolhida como "abandonada" e, portanto, disponível para adoção, os funcionários empregavam diversas táticas para deixar qualquer menção da mãe (ou outros familiares) fora do registro. 
adoções internacionais estava sendo tabulado com relativa precisão, os dados sobre adoções nacionais pareciam muito vagos. A tentativa da ONU de incluir o Brasil numa comparação estatística sobre adoção escancarou a falta de tais dados no país. Na tabela com informações sobre o número de adoções domésticas em cada um de 30 países, um rodapé alerta que, para o Brasil, constam apenas dados do estado de São Paulo (United Nations, 2009, p. 69).

Ao acompanhar adotados já adultos na sua procura (geralmente frustrada) por arquivos jurídicos versando sobre suas respectivas adoções, ouvia deles constantes suspeitas de que existia uma política coordenada de esconder informações. A alegada perda de dossiês seria resultado de um esforço deliberado de ocultar a realidade de trâmites irregulares, senão totalmente ilegais (Fonseca, 2015). Mas também escutei servidores falando de dossiês antigos, empilhados sem ordem particular em depósitos improvisados, que - se não estragados pelo mofo, incêndios ou outros acidentes do tempo - seriam praticamente impossíveis de encontrar. É bem possível - especialmente antes da difusão de tecnologias digitais - que os vários serviços governamentais simplesmente não tivessem a capacidade para armazenar de forma adequada vastas quantidades de informação. Em todo caso, até a inauguração do Cadastro Nacional de Adoção em 2008 (discutido abaixo), a opacidade de dados sobre adoções domésticas se devia em grande medida à falta de articulação federal dos vários sistemas estaduais de contagem.

Mesmo com a maior centralização de dados, não se deve ignorar a maneira com que as categorias de classificação de qualquer sistema espelham tensões políticas do momento, criando zonas de ambiguidade. Para ilustrar, recorro a um exemplo dos anos 1990, no bojo da reabertura democrática brasileira. Imperava então uma nova orientação - lançada pela Convenção Internacional dos Direitos das Crianças e consagrada pelo Estatuto (brasileiro) da Criança e Adolescente (ECA, 1990) - de que a miséria econômica não justificava separar a criança de sua família. Não era motivo nem para acolhimento institucional, nem para destituição do poder familiar. Enquanto famílias sofrendo de grande pobreza deviam ser socorridas através de programas sociais, a retirada de uma criança contra a vontade de seus pais só devia ocorrer em casos extremos de negligência, maus-tratos ou abandono pela própria família.

Para avaliar as mudanças provocadas por estes estatutos nacional e internacional, foram comparadas estatísticas de 1985 e 1994 sobre o motivo de 
ingresso de crianças no sistema institucional de acolhimento de Rio Grande do Sul (Fonseca; Cardarello, 1999). E, de fato, enquanto em 1984, as estatísticas apontavam problemas socioeconômicos ou circunstâncias semelhantes em quase $90 \%$ dos casos, em1994, classificações ligadas a problemas econômicos tinham diminuído para pouco mais de um terço dos acolhimentos. Em compensação, quase $60 \%$ dos casos tinham passado a ser classificados como resultado de abandono, maus-tratos, negligência e abuso. A pergunta que se coloca é: essa mudança de perfil se devia ao êxito da nova filosofia política que provocou maiores investimento nas famílias em dificuldade? Ou será que o próprio sistema constrangia quem preenchia os dados a favorecer classificações que responsabilizavam os pais pela situação precária de seus filhos?

Uma consideração do leque de opções classificatórias sugere que o próprio sistema ficou mais antenado a faltas cometidas pelos pais. Em 1984, existia uma distinção entre "situação de abandono" (incluindo pais não localizados ou sem condições/capacidade para cuidar dos filhos) e "abandono" (rubrica incluindo bem menos casos). Em 1994, existia apenas uma categoria - "abandono" (sem qualificações) -, representando agora o motivo mais frequente de ingresso no sistema. E, de forma significativa, nesses dez anos de intervalo, tinham surgido categorias novas apontando o dedo para pais maltratantes "abuso" e "negligência".

Contudo, devemos lembrar que as classificações inscritas nas normas e nos formulários são apenas uma parte do processo estatístico. A maneira com que cada sujeito traduz a realidade para as categorias convencionadas é outra. É precisamente nessa etapa de encoding que chegamos nas dúvidas dos próprios cadastradores. Quando entrevistada, uma assistente social responsável pelas fichas de ingresso no sistema gaúcho descrito acima admitia que, em muitas situações, a classificação do caso não estava nada clara:

Às vezes chama de negligência, mas é assistencial; se confunde. Depende da concepção de quem colocou o motivo, da conselheira tutelar ou assistente social, entendeu? O que é assistencial para uns pode ser negligência para outros. (Fonseca; Cardarello, 1999, p. 106).

É bem possível que, no preenchimento de registros, o fiel da balança pendesse em direção às categorias que justificavam a nova orientação política. Já que 
só "abandonados", "abusados" e "negligenciados" podiam ser admitidos no acolhimento, a criança ou adolescente acolhido, por definição, tinha que cair em uma dessas rubricas. Assim, era garantido que as estatísticas, cada vez mais valorizadas como instrumento de auditing, dariam prova de um serviço coerente com os princípios da política vigente. Em vez de "retratar" a realidade, estariam refletindo a lente normativa através da qual os dados eram projetados.

É evidente que muitos dos profissionais estão conscientes da fragilidade das classificações. As inconsistências no registro de dados, fruto de hesitações repletas de escolhas subjetivas, não deixam de assombrar os próprios cadastradores. Estes sabem que seguir o caminho de maior expediência imediata não elimina necessariamente as inquietações a longo prazo. Preocupam-se especialmente quando sabem que suas decisões podem fazer uma diferença dramática na vida das pessoas. Na distribuição de produtos escassos (subsídios financeiros, cestas básicas, moradia popular, etc.), já é angustiante traçar uma linha nítida de demarcação entre os mais e menos merecedores (Fassin; D’Halluin, 2005; Gupta, 2012). Na área de proteção à infância, quando a linha demarcadora pode determinar a separação de uma criança de sua família, o dilema assume proporções ainda mais dramáticas.

Outro estudo antropológico, dessa vez em um serviço público de proteção à infância na Califórnia (EUA), reflete as tentativas institucionais de atenuar essa angustiante "autonomia ética" que pesa sobre os trabalhadores sociais (Scherz, 2011). Ocorrendo em 2005, a pesquisa se desenrola num ambiente em que a administração procurava diminuir a proporção de crianças de grupos minoritários, particularmente afro-americanos, em instituições de acolhimento. Na tentativa de tornar a prática dos profissionais mais coerente com essa preocupação, o serviço introduziu um instrumento "atuarial" - uma lista de perguntas com respostas múltiplas - para avaliar a probabilidade de uma criança vir a sofrer futura violência.

Num primeiro momento, os profissionais acataram de bom grado o instrumento inovador na esperança de tornar suas decisões mais "objetivas" e, assim, diluir a responsabilidade moral de sua intervenção nas famílias. Porém, ao acompanhar o curso de treinamento e a inauguração do novo formulário, a pesquisadora começou a ouvir resmungões. Os critérios de preenchimento de cada item não estavam nada claros e, mais problemático, não existia fórmula para 
traduzir os resultados numéricos finais em recomendação específica de intervenção. Assim, opiniões sobre o nível eticamente tolerável de risco (isto é, em quais condições seria preciso remover a criança de sua família) continuavam extremamente variáveis. Para complicar ainda mais a situação, os supervisores que deviam checar a consistência das decisões passaram a interferir cada vez menos, simplesmente confiando na mediação da nova tecnologia. No saldo final, apoiando-se em reflexões weberianas, a analista sugere que os implementos tecnocráticos não substituem discussões abrangentes que enfrentam problemas éticos e políticos de fundo, e que levam em consideração a complexidade do contexto.

Lembremos que o primeiro episódio descrito acima - situado no México envolve suspeitas de abuso de autoridade contra uma mãe indígena. Os outros dois exemplos, no Brasil e nos Estados Unidos, dizem respeito também aos esforços de evitar discriminação contra famílias pobres. Esses casos empíricos são sintomáticos de uma tensão perpassando os diferentes lugares e épocas entre, por um lado, os serviços de proteção à infância e, por outro, os grupos subalternos cujos filhos são alvo particular de atenção. Assombrando a história da adoção ao longo das três últimas décadas, essa tensão endêmica no sistema teria produzido inquietações - rasgas, assim como necessários remendos - na lógica hegemônica sobre a adoção de crianças. Com múltiplas denúncias acirrando os debates, surgiu uma época de reforma, como vimos acima, dando origem a medidas legais formuladas justamente para prevenir a violação de direitos de famílias pobres e minoritárias.

Contudo, ao observar esses casos empíricos, vemos como a prática dos profissionais se desenrola, para além das orientações normativas, em espaços que são produto e produtor de informações opacas, classificações ambíguas e decisões angustiantes. Ao interagir com as várias infraestruturas, esses mediadores reconfiguram as normas que o pensamento sistêmico procura impor. Sugiro que essas reconfigurações proliferam de forma "selvagem" nas fissuras da lógica modular. Longe de serem anomalias, são elementos inerentes ao próprio sistema que dão abertura a consequências não programadas. Que estas sejam celebradas como progressistas ou lamentadas como retrógradas não altera minha hipótese geral de que a filosofia política vigente, tal como expressa nas normativas formais, não penetra em todos os espaços de modo mecânico ou uniforme, deixando margem a resultados "indomados". 


\section{Rumos políticos do novo milênio}

Devemos lembrar que nem as filosofias políticas - concatenadas nas múltiplas conexões políticas e econômicas que atravessam o globo - seguem uma evolução necessariamente linear. Analistas chamam atenção para uma convergência paradoxal de eventos que viria a atenuar o impacto das normativas internacionais do fim do último século que tentavam salvaguardar os direitos tanto das crianças quanto de suas famílias (Villalta; Gesteira, 2019). Por um lado, a Convenção Internacional dos Direitos da Criança consagrou a importância de programas promovendo a igualdade socioeconômica como parte inerente dos direitos das crianças. Por outro lado, no mesmo ano (1989) um grupo de organizações financeiras internacionais extremamente influentes formulou o Consenso de Washington, marcando a consolidação de uma política econômica neoliberal, responsabilizada por muitos pela crescente desigualdade que se intensificava mundo afora.

Em relação à proteção de crianças em situações de grande vulnerabilidade, tanto a filosofia do Estado mínimo quanto as pressões do movimento antimanicomial ditavam que o acolhimento institucional devia ser mantido ao mínimo. Porém, diante do aumento da pobreza crônica nas mais diversas regiões do mundo, ficou logo aparente que as recomendações contra o recolhimento institucional (reiteradas nos mais diversos protocolos nacionais e internacionais) não bastavam para diminuir o número de crianças e adolescentes abrigados. Sem conseguir limitar o número de jovens ingressando nas instituições públicas, os governantes teriam que encontrar maneiras para aumentar o número de egressos - e em condições em que estes não arriscavam voltar. Assim, a adoção passou a reconquistar um lugar central nas políticas públicas para a infância pobre.

A reintegração familiar, política preconizada pelas diferentes convenções internacionais, tinha se mostrado custosa e com resultados nem sempre garantidos. Em compensação, o desligamento dos jovens para uma família adotiva se tornou uma solução cada vez mais atraente. Exigia uma concentração de esforços profissionais para mediar o processo, mas - uma vez realizada a adoção -, terminava o grosso do trabalho dos serviços estatais. A responsabilidade pelo bem-estar do adotado passava irrevogavelmente para sua nova família. Assim, se alastrou pelo globo uma "nova cultura de adoção", promovida agora pelos próprios serviços públicos. O que as várias políticas nacionais tinham em comum era, por um lado, um apelo à maior celeridade do processo adotivo 
(diminuindo o tempo gasto, por exemplo, em esforços de reintegração familiar) e, por outro, a promoção de adoções "especiais", isto é, de adotados com perfil típico dos jovens em acolhimento institucional - mais velhos, não brancos e/ou com algum problema de saúde.

Em 1997, o presidente americano Clinton deu um rosto a essa guinada via o Adoption and Safe Family Act que previa a transformação de boa parte dos 500.000 "acolhidos" do sistema público em "adotados", sob responsabilidade exclusiva de suas novas famílias (Briggs, 2012). Em 2000, o governo britânico de Tony Blair, proclamando uma "nova abordagem" à adoção, manifestou sua aderência a uma semelhante guinada de perspectiva. Na Austrália, pouco tempo depois, os expertos comissionados pelo governo nacional viriam a recomendar a adoção como solução preferencial para certas crianças em grande vulnerabilidade (por exemplo, quando oriundas de famílias com usuários de drogas) (Cuthbert; Murphy; Quartly, 2009). A nova orientação se anunciou primeiro nos países anglo-saxões, mas não tardou para chegar no hemisfério sul.

No Brasil, os primeiros 15 anos depois do ECA tinham sido palco de grandes esforços para a articulação de medidas de amparo a famílias em situação de vulnerabilidade (programas de Bolsa Família, moradia popular, saúde de família, etc.), promovendo a permanência de crianças nas suas comunidades de origem. Sem dúvida, junto com o aumento do salário mínimo e um número maior de pensões para velhice e invalidez, essa multiplicação de programas sociais contribuiu para a diminuição da extrema pobreza. Apoiados nesse clima político, planos nacionais (PNAS e $\mathrm{PNCFC}^{5}$ ) reafirmavam a prioridade da "convivência familiar", relegando a adoção ao lugar de "último recurso". Entretanto, o número de crianças e, em particular, adolescentes em acolhimento institucional não diminuía na medida esperada.

Até os primeiros anos do novo milênio, o Congresso Nacional estava virando cenário para projetos de lei em que a adoção era apresentada claramente como solução para aliviar a sobrelotação dos abrigos estatais (Matias; Souza; Oliveira, 2020). Os debates congressionais refletiam a polarização já vista em outras partes do mundo entre, por um lado, aqueles que veem na adoção a melhor maneira de garantir o interesse prioritário da criança em grande vulnerabilidade e, por

5 Plano Nacional de Assistência Social (2004), Plano Nacional de Convivência Familiar e Comunitária (2006) 
outro, aqueles que suspeitam que é o Estado quem mais se beneficia dessa "medida de baixo custo que lhe permite se livrar do ônus financeiro de crianças pelas quais tem (ou poderia ter) responsabilidade" (Cuthbert; Murphy; Quartly, 2009, p. 398, tradução minha). Particularmente a partir de 2016, observa-se uma "pressão cada vez maior de projetos de lei para agilizar a destituição do poder familiar das famílias da classe trabalhadora e diminuir o tempo de espera das pessoas cadastradas para adoção" (Matias; Souza; Oliveira, 2020, p. 37).

Não é surpreendente constatar que a pressão para promover a adoção de crianças em acolhimento institucional tenha desembocado no aprimoramento de mecanismos que traduzem o processo em números. A partir de certo momento, parece ter diminuído o interesse em investigações sobre carências no sistema de proteção que dificultam a reintegração dos acolhidos nas suas famílias originais. ${ }^{6}$ A pergunta que atrai a atenção de gestores tanto quanto da mídia passa a ser: por que o processo adotivo é tão demorado? Os levantamentos agora dizem respeito aos trâmites burocráticos, responsabilizados pela "demora" no processo adotivo e consequente preponderância de crianças "de difícil colocação" (leia-se mais velhas) no sistema (Nunes, 2015). Para superar os "obstáculos à adoção", concentram-se esforços em monitorar o cumprimento dos prazos cada vez mais curtos estipulados em lei (tempo-limite de permanência no acolhimento, de abertura de processo para destituição de poder familiar, de tramitação do processo adotivo, etc.).

Mas, sem dúvida, foi o Cadastro Nacional de Adoção (CNA), inaugurado em 2008 pelo Conselho Nacional de Justiça, a inovação tecnológica mais importante na promoção de uma nova cultura de adoção no país. ${ }^{7}$ Como mencionei acima, até a inauguração do CNA, as infraestruturas de controle e execução de adoções domésticas (por pais brasileiros) tinham sido da alçada de cada estado, tornando difícil a visualização ou articulação em nível nacional. Agora, com a centralização e exibição online de certos dados, o Cadastro trouxe esperanças de transparência para um sistema assombrado pela constante suspeita de

6 A última pesquisa abrangente sobre o a rede de acolhimento no Brasil, ainda com ênfase no direito do jovem à convivência familiar e comunitária, se apoia em dados de 2011 (Assis; Farias, 2013).

7 O banco de dados passou por uma transformação radical em 2019, sendo rebatizado como "Sistema Nacional de Adoção". Nossa análise não abarca essa nova etapa que promete uma visão mais abrangente do sistema como um todo. 
favorecer um ou outro pretendente. As informações numéricas acompanhadas de gráficos coloridos, capturava a atenção da imprensa e o grande público, trazendo uma sensação de ordem tanto para profissionais quanto para adotantes.

Certamente, o novo registro representou um passo em frente para a consolidação de um sistema nacional de adoção, sem falar da facilitação de adoções interestaduais. Além do mais, os números expostos na grande imprensa batiam sempre na mesma tecla: o perfil das crianças disponíveis para adoção (mais velhas, não brancas, frequentemente com problemas de saúde) não correspondia ao que a maioria de pretendentes inscritos no Cadastro procurava. Ao que tudo parece, estes - seguindo os moldes tradicionais - queriam uma família adotiva que "imitasse a natureza"; isto é, esperavam um bebê, e com fenótipo semelhante ao deles. Servindo como instrumento pedagógico, o CNA podia levar pretendentes a flexibilizar suas expectativas e, assim, facilitar o match entre seus desejos e o perfil dos jovens "aptos à adoção" que viviam na rede de acolhimento institucional.

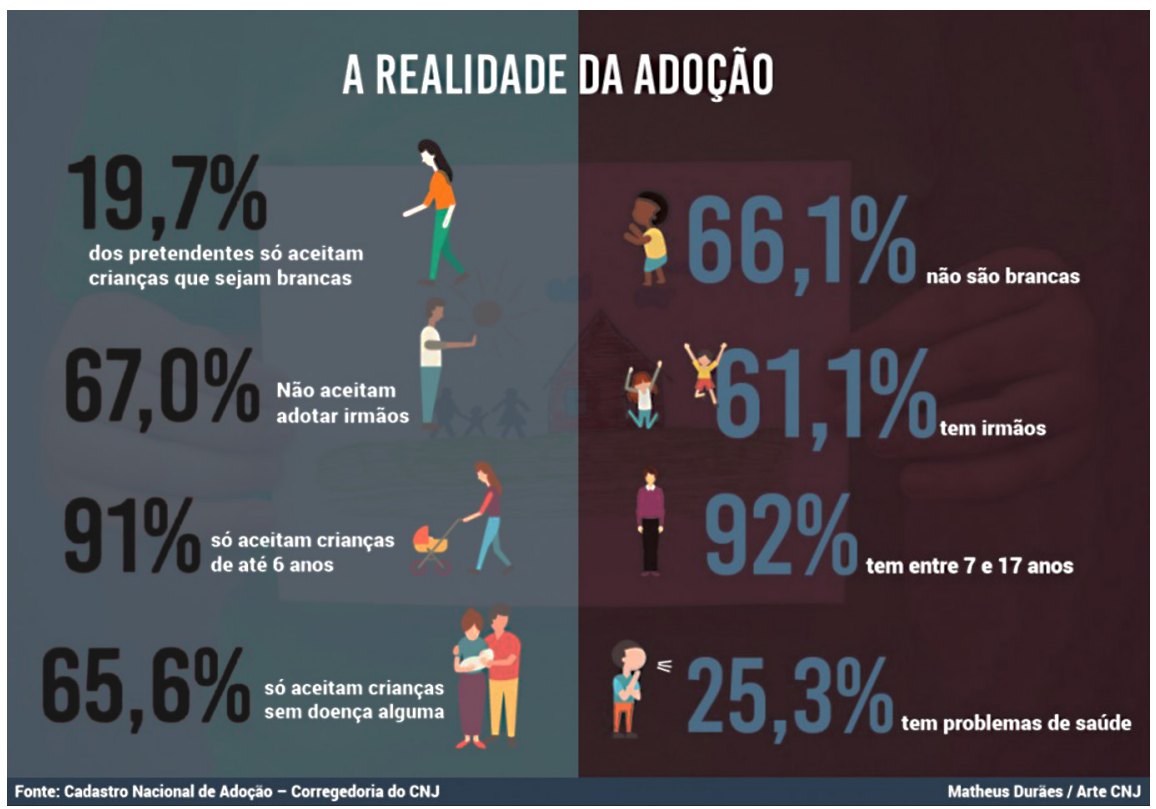

Figura 1. Um dos muitos gráficos confeccionados a partir dos dados do CNA - 2017 (Conselho Nacional de Justiça, 2017). 
Contudo, pelo menos na forma em que chegava ao grande público, havia pouca coisa nessas tabelas que pudesse ser usada para analisar o impacto das diferentes técnicas pedagógicas. Não se encontrava, entre os muitos números disponibilizados online, nenhuma série histórica (justapondo dados de anos diferentes) indicando eventuais "novas tendências" nas exigências colocadas por adotantes. Tampouco se publicava informações sobre o perfil (raça, idade) de crianças efetivamente adotadas.

De fato, ao que tudo indica, a infraestrutura cadastral não foi concebida como instrumento de pesquisa que pudesse ajudar na avaliação realista de políticas em andamento ou no planejamento de ajustes em projetos futuros. Os relatórios não incluíam uma reflexão sobre limitações metodológicas ou eventuais falhas na coleta de dados (por exemplo, o fato de que muitas comarcas e um ou outro estado não teriam aderido ao sistema nacional de registros). O mais inquietante, no entanto, na projeção desse sistema de dados diz respeito à omissão de qualquer informação sobre práticas que extrapolam os desenhos idealizados pelos administradores. Não só inexistiam informações sobre "adoções interrompidas" (em que o processo adotivo tinha sido suspenso durante o estágio preliminar de convivência ou mesmo depois), tampouco havia qualquer menção das muitas adoções legais que não constavam, nem passavam pelos procedimentos usuais da lista de espera CNA.

\section{Luz e sombra nos instrumentos de registro no caso brasileiro}

Até agora, descrevi processos que percorrem o globo, envolvendo leis e tecnologias assim como dilemas éticos e disputas políticas que guardam semelhanças em diferentes partes do mundo. Nem pioneiro nem peão, Brasil teve sua participação nessas correntes, compartilhando responsabilidade na confecção de normas internacionais e das tecnologias que vieram acompanhá-las. Mas, ao penetrar em maior detalhe nas "proliferações" atinentes ao nosso contexto, adentramos inevitavelmente em fenômenos que refletem singularidades da situação nacional.

Em concorrência com o Cadastro Nacional, existem três outras formas de adoção infantil que fazem parte das práticas tradicionais dos brasileiros. Em primeiro lugar, temos a chamada "adoção à brasileira" - um ato completamente 
ilegal, classificado como "falsidade ideológica" - que ocorre em cartório quando os pais adotivos registram a criança como se fosse filho nato. Apesar de raramente punido, é e sempre foi um crime que, entre outras violações, elimina qualquer possibilidade de o adotante rastrear suas origens por via documental. Durante a maior parte do século passado, não era difícil praticar uma adoção à brasileira justamente porque muitas crianças nasciam em casa, não sendo registradas até surgir a necessidade de um documento oficial (por exemplo, para entrar na primeira série da escola primária). Ainda nos anos 1990, autoridades públicas ousavam emitir publicamente a opinião de que essa prática era dez vezes mais comum do que a adoção legal.

Atualmente, com o quase sumiço de partos domiciliares, a consolidação de um sistema centralizado de "declaração de nascidos vivos" e a instalação de cartórios de registro civil dentro de muitas maternidades hospitalares, não há dúvida de que a maioria esmagadora de crianças recebe logo depois do nascimento um documento com o registro indelével do nome da genetriz (Richter, 2016). Mas, nos casos em que o nome do pai permanece em branco, há indicações de que, ainda hoje, um padrasto (ou outro homem) pode aceitar preencher essa lacuna na certidão de nascimento do seu enteado, colocando seu nome no lugar de genitor.

Classicamente a lei admitia a possibilidade de reconhecer os "motivos nobres" de quem perpetrava esse crime, o isentando de punição. No final de 2017, a tolerância histórica dessa prática irregular acabou se materializando em forma de uma brecha na própria lei. Ao criar o status de "paternidade socioafetiva", o provimento 63 do CNJ abriu a possibilidade de um homem (ou mulher) acrescentar seu nome na certidão do filho que está criando através de uma simples declaração em cartório. Dessa maneira, sem passar pela burocracia de uma adoção unilateral, assume irrevogavelmente todos os direitos e deveres de pai adotivo sem nunca passar pelo juizado (Fonseca, 2019). O provimento sobre paternidade socioafetiva não durou um ano sem provocar reações e novas restrições. Porém, mostra a que ponto pequenas fissuras localizadas (tal como a adoção à brasileira) podem desembocar em mudanças da própria lógica sistêmica.

Na segunda forma de adoção que corre paralela ao Cadastro Nacional, o juizado chancela um processo adotivo acordado diretamente entre a mãe (ou pais) e a família adotiva. Além de prever certa fiscalização pelo juizado, esse 
procedimento garante a preservação da identidade da criança, exigindo o registro formal dos pais tanto biológicos quanto adotivos. Conhecida variavelmente como adoção intuitu personae, direta, direcionada ou consentida, essa prática, embora prevista em lei e sancionada por sentença judicial (conforme o artigo 166 do ECA), tem sido equiparada por alguns profissionais da rede de proteção à infância à "venda" ou tráfico de bebês. A falta de legitimidade é reforçada pela falta de informações. Enquanto os dados sobre as adoções pelo CNA (supervisionadas do início até o fim pela equipe do juizado) podem conter lacunas, os dados sobre as adoções intuitu personae estão praticamente inexistentes. Aparecem só quando algum pesquisador particularmente zeloso resolve fazer um levantamento diretamente nos dossiês de determinado juizado (ver Ayres, 2008; Gueiros, 2007).

Justamente por não existir nenhuma informação em escala nacional sobre as adoções consentidas, podemos apenas levantar hipóteses à base dos diversos estudos qualitativos (Gueiros, 2007; Mariano, 2008). Supõe-se que a prática envolve crianças majoritariamente na primeira infância e nunca institucionalizadas. São transferências provocadas pela falta de recursos da família original e, antes de envolver tráfico ou "venda" de bebês, são motivadas pelo desejo da mãe ou outros membros de sua família extensa de terem uma participação na escolha da família adotiva. Apenas nessas condições, podem sentir confiança de que o bebê, em vez de passar anos no sistema institucional, será criado em condições favoráveis. Se resistem contra a modalidade de "entrega voluntária" para profissionais do tribunal, instituída por lei em 2017, é porque não se sentem à vontade com o total anonimato, a falta de participação e posterior apagamento de informações, ditados pelo protocolo estipulado.

Assim, apesar do crescente controle estatal sobre as colocações familiares, a adoção consentida - tão (se não mais) comum em certos estados quanto a adoção pelo CNA - continua com força surpreendente longe dos holofotes das estatísticas oficiais. E, tal como vimos no caso da adoção à brasileira, a presença persistente de adoções consentidas também provoca tensões com potencial de modificar o sistema. Assim, constatamos conflitos entre profissionais do sistema judicial, opondo sentenças de primeira e segunda instância quanto à possível anulação das adoções intuitu personae. Também encontramos debates no Congresso Nacional entre parlamentares propondo expandir o artigo 166, explicitando a legalidade da adoção consentida, e os que buscam apagar esse 
artigo da lei, estabelecendo a ilegalidade uma vez por todas de qualquer tramitação fora do CNA (Oliveira, 2015).

Mas talvez a forma mais inquietante de adoção que não passa pelo CNA diga respeito a um procedimento que pesquisadores apelidaram de "tráfico legal" - isto é, quando os profissionais do juizado, tendo afastado a família original, entregam as crianças a adotantes de sua escolha (Cardarello, 2009). O caso mais bem documentado é o de um juiz em Jundiaí (São Paulo), parceiro de uma ONG assistencial, que foi considerado responsável pela destituição injustificada de pátrio poder de mais de 200 mães e pela adoção subsequente de seus filhos por estrangeiros. Mas existem outros casos bem mais recentes, como o descrito nas páginas do jornal The Intercept Brasil em março de 2021. Trata-se de uma rede de servidores judiciários no Amapá, alvo de quase 200 inquéritos pendendentes no Ministério Público sobre o possível abuso de autoridade institucional para efetivar adoções irregulares. Conforme a matéria, além de "burlar" a lista de espera do CNA, as autoridades atropelaram os direitos básicos das crianças e suas famílias (Felizardo, 2021).

Esse tipo de infração é raramente denunciado, vindo a público só quando as mães conseguem encontrar uma escuta acolhedora de algum defensor ou jornalista. Algumas mulheres alegam que seus filhos foram retirados à base de acusações nunca comprovadas de maus-tratos ou negligência; outras (pelo menos, no caso de Jundiaí) denunciam que foram pressionadas por servidores a assinar documentos de entrega sem que entendessem de que se tratava (Cardarello, 2012). Contudo, apesar de denúncias na mídia, CPIs e outros inquéritos oficiais, parece que nenhum servidor tem sofrido sanções por envolvimento nesse tipo de prática e nenhuma das adoções foi anulada.

É significativo que estas duas últimas formas de adoção, embora tecnicamente legais, são raramente mencionadas nos fóruns de especialistas. Diante do público geral, a adoção pela lista de espera CNA - onde constam principalmente crianças institucionalizadas - se apresenta como a única possível. Sugiro que, nas estatísticas oficiais, o silêncio que reina sobre adoções "alternativas" seria uma forma de "ignorância estratégica" - isto é, uma maneira de negar a existência do que poderia se constituir em ameaça à aparente hegemonia estatal (no caso das adoções consentidas) ou à crença na imparcialidade do sistema (no caso do tráfico legal). Nesse quadro, o CNA faria parte das infraestruturas informacionais do pensamento modular que "ao mesmo tempo 
facilitam e embrutecem" a observação de especificidades históricas e mudanças (Tsing; Mathews; Bubandt, 2019). Sem dúvida, essa forma de esquecimento seletivo serve para preservar o impacto pedagógico do Cadastro. Porém, cabe perguntar se não dificulta uma avaliação realista do sistema de proteção à infância como um todo. É possível que, a "legibilidade do Estado" sendo apenas parcial, o feitiço volte contra o feiticeiro, criando obstáculos ao planejamento de um sistema funcional.

\section{Acenando para proliferações generativas}

Partimos neste artigo da ideia de que as tecnologias de governo se forjam no bojo de modelos abstratos, falhos e incompletos por natureza. Sem negar a força dessa maquinaria, reconhecemos a existência de áreas remendadas, crivadas de proliferações que podem ter efeitos diversos. Estas agem ora para subverter a lógica modular do sistema (como no caso dos movimentos coletivos de minorias indígenas, negras e do Sul global), ora para propiciar arranjos enjambrados, permitindo a perpetuação do sistema com apenas leves ajustes (como no caso das variáveis mediações burocráticas). Mas também existem (como nas adoções alternativas descritas acima) eventos não programados que surgem não para resistir, nem para salvaguardar as simplificações modulares, mas que acabam por provocar a possibilidade de mudanças profundas. Proponho, nesta última seção, aprofundar a exploração dessas "proliferações generativas" que emergem de colaborações engendradas pelo próprio sistema. Trata-se de ações pragmáticas, pouco teorizadas e quase sempre de pequena escala, mas que trazem a vantagem de extrapolar a imaginação de qualquer ator singular (Tsing; Mathews; Bubandt, 2019).

No hemisfério norte, em anos recentes, é sem dúvida a "voz das crianças" que tem gerado as transformações mais radicais. Adotados nascidos nos anos 1980 e 1990, chegando na vida adulta, formaram associações para expressar sua sensação de ultraje diante dos constantes obstáculos que enfrentavam na busca de suas histórias pré-adotivas. Os protestos começaram com pessoas adotadas localmente, mas ganharam fôlego com novas gerações de adotados vindo de outros países. Pessoas nascidas na África, na Ásia e nos países latino-americanos formaram movimentos coletivos junto com outros jovens que, tal 
como eles, tiveram que forjar sua identidade individual e familiar no entrecruzamento de preconcepções de raça, nação e parentesco.

Indo além da "busca de origens", muitos jovens reclamavam mais do que informações abstratas sobre suas famílias originais; queriam a possibilidade de restabelecer contato. Viam o monopólio de informações - nas mãos de pais adotivos, autoridades ou agências - como foco de seus problemas. A persistente exigência por maior transparência no processo adotivo foi aos poucos superando as previsões pessimistas dos profissionais (sobre os "traumas" que essa informação e, em particular, esse contato poderiam causar na família adotiva), desembocando em formas cada vez mais abertas de adoção. ${ }^{8}$ Conforme alguns observadores, em decorrência dessas pressões, o fluxo mediado de contatos entre a criança e suas diversas famílias está se tornando a nova norma:

[...] [O] significado "do interesse prioritário" [da criança] tem mudado historicamente à medida que as ideias sobre adoção mudaram. Trinta anos atrás, as pessoas consideravam que a "ruptura limpa" com sua família original era do interesse da criança adotada; hoje em dia, para adoções domésticas - pelo menos no Norte global -, a regra é a adoção aberta. (Cheney, 2014, p. 16, tradução minha).

Ao que tudo indica, até o momento, os adotados no Brasil não lograram se organizar em movimento com peso político semelhante. Pelo menos no arranjo idealizado pelo CNA, toda informação continua a ser concentrada nas mãos dos profissionais do juizado, as famílias biológicas permanecem totalmente afastadas dos trâmites adotivos, e o contato entre uma criança adotada e sua família original é, até hoje, exceção antes do que regra. Entretanto, pesquisas pontuais sugerem que - especialmente em anos recentes - a "voz das crianças" está surgindo em espaços inesperados. Para ilustrar, recorro a um exemplo perto de minha casa (Porto Alegre, 2019), ressaltando as ideias introduzidas por João, autodeclarado "negro, gay, órfão e militante". ${ }^{9}$

8 Para uma discussão sobre adoção aberta, ver o recente artigo de Melo (2021) e a mesa-redonda do IBDCRIA (Adoção..., 2021).

9 As entrevistas com João foram realizadas por Bianca Peixoto Nitschke no decorrer da pesquisa para sua monografia de conclusão de curso de ciências sociais (Nitschke, 2019). 
Abrigado há mais de oito anos, João - já com 18 anos e a ponto de sair do sistema - tem experimentado na pele as últimas mudanças de política institucional. Especialmente desde a chegada de uma nova equipe na Corregedoria da Infância e Juventude do Rio Grande do Sul em 2016, se encontrou enquadrado nas campanhas que promovem a adoção de jovens "de difícil colocação". Acreditando que ajudaria na adoção de seus cinco irmãos mais moços (também acolhidos), João tinha aceitado colocar seu nome na lista de "disponíveis à adoção". Ao mesmo tempo, aproveitou um convite para integrar o Comitê de Participação de Adolescentes Acolhidos na Justiça (CPAAJ), criado em 2018 com o intuito de "dar voz" aos acolhidos mais maduros. Nesse espaço, reúnem-se mensalmente dez jovens abrigados junto com autoridades de alto escalão para debater questões que vão da sexualidade até medidas de desligamento e adoção. No momento da entrevista, João, já no seu último ano de estudo em um colégio particular, estava prestes a começar sua formação em Direito. Por força de seus talentos intelectuais e uma personalidade imponente, sempre conseguira as bolsas necessárias para seguir a carreira de sua escolha e, agora, articulava para a entrevistadora uma série de comentários desafiadores.

Na sua narrativa, João deixa clara uma extraordinária empatia pela mãe, já falecida há anos. Lembra que, inicialmente, quando abordada pelos trabalhadores sociais, ela não entendia nada do que falavam para ela, não imaginava que alguém pudesse lhe retirar os filhos. Mesmo doente, tentou "se organizar". Até conseguiu estabelecer moradia fixa e visitar os filhos no abrigo, mas simplesmente não tinha possibilidade de chegar num patamar considerado sem risco. Sem dúvida, em parte por causa dessas memórias, João estranhou a proposta dos administradores de "encontrar uma família" para ele. Já com 15 anos quando as campanhas de adoção tardia começaram a ser intensificadas, ele coloca a pergunta: "Será que era isso mesmo que eu queria?" Sublinha a sensação de que a administração não procurava escutar o jovem acolhido "conforme a história dele": "Eu tinha figura materna na minha vida... Tinha uma figura inadequada nos termos da lei, mas tinha." $\mathrm{Na}$ opinião dele, os adotantes potenciais dos quais ele recebia visitas tampouco entendiam o que representa a adoção "tardia": "Eles não me viam da forma de um adolescente que merecia um suporte. Eles queriam um filho, um bebê." 
João vê parte desses desentendimentos como consequência das infraestruturas que conduzem o processo adotivo - mal adaptado ao caso de jovens mais maduros. Expressa o desejo de ver categorias mais simétricas sobre, por exemplo, os perfis do adotante e o adotando:

Os possíveis pais adotivos falam tanto de perfis e nós não falamos de perfis de pais. Acho que nunca fomos numa entrevista de abrigo e perguntaram qual o perfil de pai ideal que eu queria. (cf. Nitschke, 2019, p. 68).

Fala do fluxo desigual de informações: "Gente, ela [a adotante em potencial] sabia tudo da minha vida e eu não sabia nada dela. [...] Isso é sem noção. É inadmissível." E sublinha o caráter enviesado da informação sobre os "aptos à adoção" que a administração passa para os pais pretendentes. À imagem "romantizada", fornecida no primeiro contato pelo aplicativo (até com vídeos em que o jovem se apresenta), segue uma versão da vida do jovem dramatizada pela equipe técnica: “Sabe, aquilo de que 'depressivos são fofos'? É literalmente um romance. Eles estão invertendo a lógica do que realmente é." No entender de João, ao relatar que o acolhido passou por isso ou aquilo, o descrevendo em termos de traumas passados, a equipe técnica alimenta estereótipos de fragilidade psicológica diante da qual os pais adotivos podem se sentir os "salvadores da pátria" (cf. Nitschke, 2019, p. 68).

Mas o que mais provoca a indignação de João é o "racismo institucionalizado" - na forma da infraestrutura que permite aos pretendentes escolherem o "perfil" da criança que querem adotar. No entender dele, o formulário inicial (em que pretendentes estipulam sua preferência conforme o gênero, a idade e a cor da criança) não só revela quais os acolhidos mais desejáveis, mas "identifica aqueles que não estão sendo adotados e os expõe" (Nitschke, 2019, p. 64). Vendo a insistência no perfil como uma "pontuação" das crianças, João lembra que o processo adotivo envolve, grosso modo, pais brancos recebendo crianças de pele negra. E, mesmo admitindo que a idade do acolhido possa ser relevante, insiste que a distinção por etnia é inadmissível. "Os pais adotivos não têm que receber a resposta que eles querem." Devem estar buscando filhos adotivos e não perfis, pessoas e não números.

Nos últimos anos, a "adoção tardia" virou carro-chefe de campanhas em diferentes estados do Brasil, com a organização de eventos em estádios de 
futebol, em centros comerciais e outros lugares festivos para colocar em destaque adolescentes acolhidos disponíveis para adoção. Nessas campanhas, não transparece qualquer dúvida sobre os benefícios que a adoção trará para o adolescente. Parece autoevidente que o próprio adotado dará sem hesitação seu consentimento (necessário para a adoção de qualquer criança acima de 12 anos). E, de fato, muitos abrigados abraçam com entusiasmo a ideia de ser adotado - enfim, de ter um lugar onde ir depois de sair do abrigo, de poder contar com um adulto (ou adultos) da geração mais velha legalmente incumbido de zelar pelo seu bem-estar. (O próprio João achou uma boa opção para os irmãos mais moços.) Assim, a narrativa oficial coloca a adoção como principal via e as atitudes preconceituosas dos adotantes como principal obstáculo a uma bem-sucedida vida do jovem acolhido. Decorrem daí as campanhas educativas organizadas pelo juizado para sensibilizar as pessoas na lista de espera quanto às possibilidades gratificantes de adotar uma criança mais velha.

O discurso de João tensiona a narrativa encontrada nessas recentes campanhas. Seus comentários suscitam a pergunta: quais outras opções, além da adoção, estariam abertas ao jovem abrigado? A legislação prevê um máximo de 18 meses de acolhimento, depois do qual a criança deve retornar à família ou entrar na lista de "disponíveis para adoção". Não há nenhuma política prevista de acolhimento a longo prazo. Nos casos em que a reintegração familiar é pouco provável, o jovem pode recusar ser "disponibilizado" à adoção? Quantas histórias ouvimos sobre adolescentes "disponíveis" que, ao serem visitados no abrigo por um pretendente a pai adotivo, simplesmente ignoraram o visitante. É possível que esses jovens recalcitrantes, tal como João, ainda mantenham uma forte identidade familiar - vínculos não só com os pais (mesmo falecidos), mas também com os irmãos - e não aceitem facilmente a ideia de uma adoção plena que apagaria o registro dessa família. É possível que, tendo observado a proporção relativamente alta de adolescentes com processos adotivos interrompidos, não levem muita fé nessa possibilidade. Mas também é possível que estejam expressando um protesto contra um procedimento em que - rotulados como sendo de "difícil colocação" - aparecem como pessoas necessitadas à espera de uma boa alma para resolver seus problemas. Enfim, pensar que você é um entre os $83 \%$ dos abrigados acima de sete anos sendo considerado por um daqueles $8 \%$ dos pais adotivos que 
aceitam um filho nessa idade ${ }^{10}$ pode criar a sensação de certo desequilíbrio de poder.

É importante observar que, não obstante suas críticas, João em momento algum recrimina os funcionários e profissionais que cuidam dele há pelo menos oito anos. Pelo contrário, dá a impressão de uma cumplicidade quase familiar entre ele (e seus colegas) e os adultos que administram a casa-lar onde passou tanto tempo. Do jeito que formula os comentários, é claramente o sistema (e não as pessoas particulares) que está perpetrando abusos. Ainda mais, cabe notar que as observações de João emergem junto com o processo participativo em que ele foi envolvido pela Corregedoria - o conselho de jovens abrigados. De certa forma, é o próprio sistema que está criando possibilidades para ele firmar sua "voz".

Não é por acaso que hoje, no hemisfério norte, a corrente analítica que mais desafia as narrativas salvacionistas do passado - isto é, os "estudos críticos da adoção" - é propulsionada majoritariamente por pesquisadores adotados na infância. Trata-se de pessoas que, tal como João, mostram a combinação de acuidade intelectual, autoestima e desenvoltura necessária para projetar uma reformulação profunda das estruturas que guiaram suas vidas. Sugere-se que foi apenas com a entrada desses jovens no debate acadêmico que simplificações românticas do processo adotivo, promovidas num primeiro momento por pesquisadoras/mães adotivas, começaram a ruir. Essa nova geração de analistas não encara a adaptação ao país adotivo, nem a criação de vínculos, ou a assimilação ao status de filho nato da família como critérios necessários de sucesso. Antes de almejar algum tipo de normalidade predefinida, reivindica uma identidade própria, capaz de chacoalhar as bases valorativas do próprio sistema (Wichelen, 2014). Adaptando essas provocações ao contexto brasileiro, levanto a sugestão de que as guinadas mais promissoras - as proliferações generativas - no campo de adoção emergirão do que aprendemos justamente com os casos bem-sucedidos - isto é, das pessoas que vivenciaram o sistema por dentro e que colocam essa experiência ao serviço de sugestões críticas para sua reforma. De uma maneira ou outra, em vista das tantas transformações em anos recentes, a “adoção”, sem dúvida, haverá de passar por uma ressignificação radical.

10 Dados para Rio Grande do Sul, 2017 (Gonçalves, 2017). 


\section{Considerações finais}

Tsing, Mathews e Bubandt (2019) apresentam sua proposta analítica como uma maneira de enfrentar a relação problemática entre, por um lado, os princípios iluministas que guiam o pensamento sistêmico das políticas de intervenção e, por outro, a complexa particularidade das persistentes desigualdades sociais, políticas e econômicas que assolam o mundo. Ao elaborar a noção de proliferações selvagens, deixam entender que é pela atenção aos "remendos" do sistema em pontos específicos, onde o desenho original previsto foi surpreendido por obstáculos inesperados, que podemos visualizar não só a violência da desigualdade, mas também maneiras plausíveis para combatê-la. Esses remendos, os autores sugerem, são muitos. Porém, são rotineiramente invisibilizados pelos instrumentos de coletar dados e retratar a realidade que "banem o poder dos exemplos". Caberia à antropologia resgatar essas "histórias contingentes" e colocá-las em destaque para que assumam um papel central nos planos do futuro.

Ao focar neste artigo as infraestruturas no campo da adoção - metas, gráficos e formulários -, procurei dar materialidade a esses instrumentos de coleta e descrição. Reconheceu-se a agência dos artefatos burocráticos, isto é, sua influência sobre as perspectivas dos administradores e, por extensão, a realidade dos administrados. Porém, também vimos como, constantemente balançada por eventos imprevistos, essa influência pode ser traduzida em práticas com consequências muito diversas. "Doadores" de crianças podem, em movimento coletivo, aproveitar estatísticas para protestar seu lugar subalterno no sistema. Contrariamente, em manobras individuais, podem se esquivar às estatísticas para gozar da liberdade de uma vida à margem das normas vigentes. Mediadores, numa tentativa de exibir sua competência, podem formular seus instrumentos de registro de forma a realçar uma imagem bem-sucedida de suas políticas de intervenção. Por outro lado, introjetam suas ansiedades e perspectivas morais nos procedimentos administrativos, recriando classificações ou introduzindo ajustes na codificação de dados, de forma a produzir resultados que têm pouco a ver com o desenho original dos planejadores. Finalmente, jovens, tendo passado pela experiência de ser "aptos à adoção", encontram maneiras diversas para analisar, criticar e até evitar as regras esquemáticas formuladas ostensivamente para garantir a prioridade de seus 
interesses. Sugiro que, devido a essas proliferações indomáveis - e não por desenho -, chegamos neste novo milênio a uma transformação substancial dos atores pivôs no processo adotivo, abrindo o caminho para possibilidades futuras ainda mal vislumbradas. Com a proposta de Tsing, Mathews e Bubandt como norte, trouxe para o debate esses espaços remendados do sistema de proteção à infância, não como problemas e, sim, como oportunidades produtivas, na esperança de que poderão ensejar um leque maior e, quem sabe, mais reflexivo de caminhos imaginados.

\section{Referências}

ADOÇÃO aberta (ou com contato): um debate por se fazer no Brasil. Mesa-redonda publicada no canal Extensão UNISAL. [S. l.]: IBDCRIA-ABMP, 12 fev. 2021. 1 vídeo (161min). Disponível em: https://www.youtube.com/watch?v=PHp3u2puJP4. Acesso em: 10 maio 2021.

ASSIS, S. G.; FARIAS, L. O. (org.). Levantamento nacional das crianças e adolescentes em serviço de acolhimento. São Paulo: Hucitec, 2013.

AYRES, L. S. M. Adoção: de menor a criança, de criança a filho. Curitiba: Juruá Editora, 2008.

BALLARD, R. L. et al. (ed.). The intercountry adoption debate: dialogues across disciplines. Newcastle upon Tyne: Cambridge Scholars Publishing, 2015.

BALLESTERO, A. Transparency in triads. PoLAR: Political and Legal Anthropology Review, [s. l.], v. 35, n. 2, p. 160-166, 2012.

BOWKER, G. C.; STAR, S. L. Sorting things out. Cambridge: MIT Press, 1999.

BRASIL erradica sub-registro civil de nascimento. Governo Federal: Ministério da Mulher, da Família e dos Direitos Humanos, Brasília, 2 dez. 2015. Disponível em: https://www.gov.br/mdh/pt-br/sdh/noticias/2015/dezembro/brasil-erradica-sub-registro-civil-de-nascimento. Acesso em: 10 maio 2021.

BRIGGS, L. Somebody's children: the politics of transracial and transnational adoption. Durham: Duke University Press, 2012.

BRUNO, I.; DIDIER, E. Benchmarking: l'État sous pression statistique. Paris: Zones, 2013. 
CARDARELLO, A. The movement of the mothers of the courthouse square: "legal child trafficking", adoption and poverty in Brazil. Journal of Latin American and Caribbean Anthropology, [s. l.], v. 14, n. 1, p. 14-161, 2009.

CARDARELLO, A. O interesse da criança e o interesse das elites: "escândalos de tráfico de crianças", adoção e paternidade no Brasil. Scripta Nova, [s. l.], v. 16, n. 395, 2012. Disponível em: http://www.ub.es/geocrit/sn/sn-395/sn-395-10.htm. Acesso em: 10 maio 2021.

CHENEY, K. Executive summary of the International Forum on Intercountry Adoption and Global Surrogacy. The Hague: International Institute of Social Service, 2014. (Working Paper $n^{\circ} 596$ ).

CONSELHO NACIONAL DE JUSTIÇA. Adoção de criança: um Cadastro Nacional mais transparente e ágil. Brasília: CNJ, 2 maio 2017. Disponível em: https://www.cnj. jus.br/adocao-de-crianca-um-cadastro-nacional-mais-transparente-e-agil/. Acesso em: 10 maio 2021.

CUTHBERT, D.; MURPHY, K.; QUARTLY, M. Adoption and feminism. Australian Feminist Studies, [s. l.], v. 24, n. 62, p. 395-419, 2009.

DESROSIÈRES, A. La politique des grands nombres. Paris: La Découverte, 1993.

FASSIN, D.; D'HALLUIN, E. The truth from the body: medical certificates as ultimate evidence for asylum seekers. American Anthropologist, [s. l.], v. 107, n. 4, p. 597-608, 2005.

FELIZARDO, N. “Esqueça a sua filha”. Casais ricos do Amapá driblam Lei da Adoção e tiram crianças de famílias pobres com apoio do judiciário. The Intercept Brasil, Rio de Janeiro, 15 mar. 2021. Disponível em: https://theintercept.com/2021/03/15/casais-ricos-driblam-adocao-apoio-judiciario-amapa/. Acesso em: 10 maio 2021.

FONSECA, C. Pertencimento familiar e hierarquia de classe: segredo, ruptura e desigualdade vistos pelas narrativas de adotados brasileiros. Áltera: Revista de Antropologia, João Pessoa, v. 1, n. 1, p. 9-36, 2015.

FONSECA, C. DNA and the displacement of certainties in Brazilian family law. Sexualidad, Salud y Sociedad, Rio de Janeiro, n. 32, p. 4-19, ago. 2019.

FONSECA, C.; CARDARELLO, A. Direitos dos mais e menos humanos. Horizontes Antropológicos, Porto Alegre, ano 5, n. 10, p. 83-122, maio 1999.

GONÇALVES, G. Filhos do sistema. In: UNISINOS INVESTIGA, [s. l.], 11 jul. 2017. Disponível em: https://medium.com/unisinos-investiga/filhos-do-sistema-980359db7ae2. Acesso em: 10 maio 2021. 
GUEIROS, D. Adoção consentida: do desenraizamento social da família à prática de adoção aberta. São Paulo: Cortez, 2007.

GUPTA, A. Red tape: bureaucracy, structural violence, and poverty in India. Durham: Duke University Press, 2012.

HACKING, I. Taming of chance. Cambridge: Cambridge University Press, 1990.

HIRATA, D. et al. Échanges de tirs: la production de données sur la violence armée dans des opérations de police à Rio de Janeiro. Statistique et Sociéte, [s. l.], v. 7, n. 1, p. 31-39, 2019.

INSTITUTO BRASILEIRO DE GEOGRAFIA E ESTATÍSTICA. Coordenação de População e Indicadores Sociais. Gerência de Estudos e Pesquisas Sociais. Estatísticas do Registro Civil - 2019. Brasília: DPE/IBGE, 2020. Disponível em: https://agenciadenoticias.ibge.gov.br/media/com_mediaibge/arquivos/ce2c26b7378982c66ff2f18ed73f0ed2.pdf. Acesso em: 10 maio 2021.

LARKIN, B. The Politics and poetics of infrastructure. Annual Review of Anthropology, Palo Alto, v. 42, p. 327-443, 2013.

MARIANO, F. N. Adoções "prontas" ou diretas: buscando conhecer seus caminhos e percalços. 2008. Tese (Doutorado em Ciências) - Faculdade de Filosofia, Ciências e Letras, Universidade de São Paulo, Ribeirão Preto, 2008.

MATIAS, D. S. G.; SOUZA, N. O.; OLIVEIRA, R. C. S. 30 anos de estatuto da criança e do adolescente: (re)encontrando algumas marcas e marcos de sua construção, tramitação e implementação. Boletim NCA-SGD, São Paulo, n. 2, p. 2-50, out. 2020.

McGOEY, L. The logic of strategic ignorance. The British Journal of Sociology, [s. l.], v. 63, n. 3, p. 553-576, 2012.

MELO, E. R. Adoção com contato e direitos da criança e do adolescente: uma problematização de paradigmas. In: VIEIRA, M. de M.; BARCELOS, P. T. R. (org.). Direitos da criança e do adolescente: o direito à convivência familiar em foco. São Paulo: Editora D’Placido, 2021. p. 169-216.

MERRY, S. E. Measuring the world: indicators, human rights, and global governance. Current Anthropology, [s. l.], v. 52, supl. 3, p. 583-595, 2011.

NITSCHKE, B. P. Deixa o amor te surpreender: adoções de difícil colocação nas atuais políticas brasileiras. 2019. Trabalho de conclusão de curso (Bacharelado em Ciências Sociais) - Instituto de Filosofia e Ciências Humanas, Universidade Federal do Rio Grande do Sul, Porto Alegre, 2019. 
NUNES, M. C. (coord.). Processos relacionados à adoção no Brasil: uma análise sobre os impactos da atuação do Poder Judiciário. Brasília: Conselho Nacional de Justiça, 2015.

OLIVEIRA, R. C. S. No melhor interesse da criança?: a ênfase na adoção como garantia do direito à convivência familiar e comunitária. 2015. Tese (Doutorado em Serviço Social) - Pontifícia Universidade Católica de São Paulo, São Paulo, 2015.

PINTO, A. E. Em busca dos pais biológicos, brasileiro muda regra de adoção na Holanda. Folha de S. Paulo, São Paulo, 26 fev. 2021. Disponível em: https://www1. folha.uol.com.br/mundo/2021/02/em-busca-dos-pais-biologicos-brasileiro-muda-regra-de-adocao-na-holanda.shtml. Acesso em: 10 maio 2021.

REYES-KIPP, A. C. New lives for children: adoption documents and the law in Central Mexico. In: HAN, C.; DAS, V. (ed.). Living and dying in the contemporary world: a compendium. Berkeley: University of California Press, 2016. p. 100-113.

RIBEIRO, F. B. O nome da lei: violências, proteções e diferenciação social de crianças. In: FONSECA, C.; MEDAETS, C.; RIBEIRO, F. R. (org.). Pesquisas sobre família e infância no mundo contemporâneo. Porto Alegre: Sulina, 2018. p. 41-65.

RICHTER, V. S. Nascimento dos dados: artefatos e mediações nas práticas cotidianas da produção da população em Porto Alegre, Brasil. In: FONSECA, C. L. W. et al. (org.). Ciência, medicina e perícia nas tecnologias de governo. Porto Alegre: Editora da UFRGS: CEGOV, 2016. p. 61-86.

SCHERZ, C. Protecting children, preserving families: moral conflict and actuarial science in a problem of contemporary governance. PoLAR: Political and Legal Anthropology Review, [s. l.], v. 34, n. 1, p. 33-50, 2011.

SCHUCH, P. Direitos humanos e as pessoas em situação de rua no Brasil: discutindo a legibilidade. In: SOUZA LIMA, A. C. et al. (org.). A antropologia e a esfera pública no Brasil: perspectivas e prospectivas sobre a associação brasileira de antropologia no seu $60^{\circ}$ aniversário. Brasília: ABA; Rio de Janeiro: E-Papers, 2018. p. 303-328.

SCOTT, J. Seeing like a state: how certain schemes to improve the human condition have failed. New Haven: Yale University Press, 1998.

SHORE, C.; WRIGHT, S. Policy: a new field of anthropology. In: SHORE, C.; WRIGHT, S. (ed.). Anthropology of policy: critical perspectives on governance and power. New York: Routledge, 1997. p. 3-33.

TSING, A. L.; MATHEWS, A.; BUBANDT, N. Patchy Anthropocene: landscape structure, multispecies history, and the retooling of anthropology. Current Anthropology, [s. l.], v. 60, supl. 20, p. S186-S197, Aug. 2019. 
UNITED NATIONS. Child adoption: trends and policies. New York: UN, Department of Economic and Social Affairs, Population Division, 2009.

UNITED NATIONS CHILDREN'S FUND. Every child's birth right: inequities and trends in birth registration. Geneva: UNICEF, Data and Analytics Section, Division of Policy and Strategy, 2013.

VILLALTA, C.; GESTEIRA, S. (dir.). La Convención sobre los Derechos del Niño en la Argentina: trayectorias, experiencias y activismo. Buenos Aires: UNICEF, 2019.

WICHELEN, S. van. Medicine as moral technology: somatic economies and the making up of adoptees. Medical Anthropology: Cross-Cultural Studies in Health and Illness, [s. l.], v. 33, n. 2, p. 109-127, 2014.

Recebido: 12/05/2021 Aceito: 13/05/2021 | Received:5/12/2021 Accepted:5/13/2021 